Jorge Antonio Di Nicco

Pontifical Catholic University of Argentina

\title{
La administración de los bienes de la Iglesia hasta el siglo $X$ : algunas de las disposiciones, especialmente de los concilios, y su recepción en el Código de Derecho Canónico de Juan Pablo II
}

The administration of Church property until the tenth century: some of the provisions, especially the councils, and its reception in the Code of Canon Law by John Paul II

\begin{abstract}
This article analyses the evolution of the goods of the Church and its administration during the first millennium of the Christian era. It reveals the first community of Jerusalem where believers had everything in common, discusses the centrality of the Bishop and severely damaging mismanagement, and some of the provisions on the subject under study, especially those arising from the various councils. It talks about the attempts and tendencies towards the disintegration of the diocesan heritage as a unitary whole from the sixth century; notwithstanding which, the Bishop has the responsibility for his subordinate entities, keeping the administrative power over the property of the diocese. In the last part, the article presents several of these provisions in the Code of Canon Law by John Paul II.
\end{abstract}

\section{Keywords}

Administration of Church property, councils, finance officer. 
En las bienaventuranzas se encuentran comprendidas todas las enseñanzas de Jesús acerca de los bienes temporales. ${ }^{1}$

Jesús y los Apóstoles poseían bienes para su sustento y para obras de caridad (Juan 12, 4-6 y 13, 27-29). Jesús no rechaza los bienes materiales, sino que los ubica en el lugar y en la finalidad que les corresponden. Él nos muestra que los bienes deben ser correctamente administrados (Juan 6, 12). ${ }^{2}$

Se cita a Mateo 10, 9-10 y a Lucas 10, 7-8 como "Fontes Divini Iuris Evangelia, Juris Patrimonialis Ecclesiae"; y a dos epístolas de Pablo, la primera epístola a los Corintios 9, 13 y la epístola a los Gálatas 6, 6, como "Fontes Divini Iuris Litterae Apostolicae".

Durante el transcurso del primer milenio de la era cristiana se observa una interesante evolución en cuanto la administración de los bienes eclesiásticos. Las disposiciones en tal sentido son elocuentes en ese período. Al análisis de algunas de esas disposiciones, que se ven reflejadas en el Código de Derecho Canónico de 1983, se dedica el presente estudio.

\section{Las primeras comunidades cristianas (siglos I, II y III)}

En la primera comunidad de Jerusalén todos los creyentes tenían todo en común, vendían sus posesiones y sus bienes y lo repartían entre todos, según la necesidad de cada uno, nadie consideraba sus bienes como propios, sino que todo lo ponían a los pies de los Apóstoles para ser dado a cada uno según su necesidad (Hechos 2, 44-45; 4, 32-35). ${ }^{4}$

Estamos frente al ideal de la comunidad cristiana, con la finalidad de los bienes temporales para las obras, en particular, de caridad y piedad. ${ }^{5}$

${ }^{1}$ Cfr. V. De Paolis, I beni temporali della Chiesa, Bologna 1995, p. 246-247.

${ }^{2}$ Cfr. J. A. Di Nicco, El Ecónomo Diocesano. Precisiones acerca de este oficio eclesiástico. Propuesta sobre el parágrafo tercero del canon 494, Buenos Aires 2012, p. 12-13.

${ }^{3}$ Cfr. A. Barile, De Patrimoniali Ecclesiae Regimine, Historica vel juridica praesupposita, Roma 1925, p. 72.

${ }^{4}$ Estos principios fundacionales operan implícitamente en la legislación de la Iglesia sobre sus bienes temporales. Cfr. V. G. D'Souza, General Principles Governing the Administration of Temporal Goods of the Church, en: V. G. D'Souza (ed.) In the Service of Truth and Justice. Festschrift in Honour of Prof. Augustine Mendonça Professor Emeritus, Bangalore 2008, p. 497.

${ }^{5}$ Ver A. Perlasca, Il concetto di bene ecclesiastico, Roma 1997, p. 15-22; V. De Paolis, I beni temporali..., op. cit., p. 247-249; V. De Paolis, Les biens temporels au regard du code de droit 
La unidad sobrenatural en Cristo, a través de su Santo Espíritu, es el fundamento de la comunión de bienes, todo viene de Dios que quiere que los bienes sirvan a todos. ${ }^{6}$

La comunión de bienes, ideal propuesto por san Lucas en los Hechos de los Apóstoles, realiza no sólo el ideal del Antiguo Testamento sino también del mundo pagano: "las cosas de los amigos son comunes".

Los Apóstoles no eran los nuevos propietarios del producto de la venta de los bienes ofrendados, sino que eran simplemente sus administradores. ${ }^{8}$

Los bienes temporales que provenían de las ofrendas de los fieles más acomodados eran distribuidos por los ministros. ${ }^{9}$

Por aquellos días, leemos en los Hechos de los Apóstoles, al multiplicarse los discípulos, hubo quejas de los helenistas contra los hebreos, porque sus viudas eran desatendidas en la asistencia cotidiana. Los Doce convocaron la asamblea de los discípulos y dijeron: "No está bien que nosotros abandonemos la palabra de Dios por servir a las mesas. Por tanto, hermanos, buscad de entre vosotros a siete hombres de buena fama, llenos de Espíritu y de saber, y los pondremos al frente de esa tarea; mientras que nosotros nos dedicaremos a la oración y al ministerio de la palabra" (Hechos 6, 1-4).

Y así fueron elegidos Esteban, Felipe, Prócoro, Nicanor, Timón, Pármenas y Nicolás (Hechos 6, 5).

El término diácono significa servidor, y si bien san Lucas no da ese nombre a los siete elegidos, repite la palabra servicio (diakonía). ${ }^{10}$

Con este término se designa una categoría especial de ministros que servían a la comunidad, ocupándose de los pobres y cumpliendo funciones administrativas. Se ubicaban en el tercer lugar en la jerarquía eclesiástica, y en su ministerio

canonique, "Lannée Canonique" tome 47 (2005) 33-35; V. Mosca, Il ruolo della gerarchia nellamministrazione comunionale dei beni della chiesa, en: Iustitia in Caritate, cittá del Vaticano 2005, p. 387- 388, 392-393.

${ }^{6}$ Cfr. V. De Paolis, I beni temporali..., op. cit., p. 249.

${ }^{7}$ Cfr. V. De Paolis, Les biens temporels..., op. cit., 34; V. De Paolis, I beni temporali..., op. cit., p. 247; A. Perlasca, Il concetto di..., op. cit., p. 16-17.

${ }^{8}$ Cfr. A Perlasca, Il concetto di..., op. cit., p. 21.

9 Cfr. F. R. Martínez Aguilar, Las normas sobre la administración económica en las Iglesias particulares. En especial su aplicación en el derecho particular del cono sur latinoamericano, Montevideo 1998, p. 7.

${ }^{10}$ Cfr. S. García, Comentario Hechos de los Apóstoles 6, 5, en: Biblia de Jerusalén. Nueva edición revisada y ampliada (dirección J. Á. Ubieta López), Bilbao 19983, p. 1602. 
eran, además, colaboradores de los Obispos en la administración de los bienes que la comunidad destinaba a los necesitados en la Iglesia. ${ }^{11}$

De ahí que los diáconos debían ser personas dignas, no dados a beber mucho vino ni a negocios sucios; y quienes ejercían bien el diaconado alcanzaban un puesto honroso, y en la fe de Cristo, grande entereza. ${ }^{12}$

Las primeras generaciones cristianas rigieron la vida colectiva de las comunidades aplicando los textos del Nuevo Testamento, la tradición apostólica, las costumbres y las decisiones que adoptaban los Obispos en su calidad de sucesores de los Apóstoles. ${ }^{13}$

En cuanto a la elección de Obispos y diáconos, la Didaché expresaba que debían ser dignos del Señor, "hombres mansos, desinteresados, verdaderos y probados, porque también ellos os administran el ministerio de los profetas y maestros". ${ }^{14}$

A comienzos del siglo II se apreciaba la centralidad y supremacía del Obispo, que ocupaba el lugar de Dios. A su vez, los presbíteros tomaban el lugar del senado de los Apóstoles, y el servicio de Jesucristo queda confiado a los diáconos. Los bienes, dones y ofrendas eran bienes del Señor, ya que eran ofrecidos, normalmente en la celebración de la eucaristía, a Él. Y si los dones pertenecían a Dios, su administración sólo podía ser una misión reservada a los sacerdotes, y en particular al Obispo. ${ }^{15}$

Lo gravemente perjudicial de una administración mala llevó a decir al Pastor de Hermas que "los que tienen manchas son los ministros o diáconos que administran mal, saqueando la vida de las viudas y huérfanos y haciéndose una fortuna de lo que recibieron para administrar. Ahora bien, si persistieren en su codicia, dense por muertos y ninguna esperanza les queda de vida." ${ }^{16}$

Como se observa, se resalta la gran preocupación que existía por la honestidad de aquellos que debían tener a su cargo administrar los bienes destinados a los pobres.

${ }^{11}$ Cfr. F. R. Martínez Aguilar, Las normas sobre..., op. cit., p. 8.

12 Cfr. 1 Timoteo 3, 8-10 y 13.

13 Cfr. P Lombardía, Lecciones de Derecho Canónico. Introducción, Derecho Constitucional, Parte General, Madrid 19913, p. 28.

14 D. Ruiz Bueno, Padres Apostólicos, Madrid 19855, p. 92.

${ }^{15}$ Cfr. F. R. Martínez Aguilar, Las normas sobre..., op. cit., p. 9-10.

16 D. Ruiz Bueno, Padres Apostólicos ..., op. cit., p. 1079-1080. 
Los Obispos, en las pequeñas comunidades del sigo II, eran los principales responsables de la beneficencia que frecuentemente ejercitaban en primera persona; siendo, a veces, asociados a ellos los presbíteros y los diáconos. ${ }^{17}$

El Obispo, administraba las donaciones frutos de las colectas y con eso proveía a los diáconos, a las viudas, a los niños, a los indigentes y a los peregrinos ${ }^{18}$; pero con el correr del tiempo los diáconos, siempre bajo la vigilancia del Obispo, pasan a ser los principales responsables del ejercicio de la actividad de beneficencia debido al continuo crecimiento de las obras de caridad. ${ }^{19}$

Lo que queda en claro durante este período posapostólico es que la autoridad del Obispo debe prevalecer, sin que nadie le pida cuentas ni le observe cómo realiza su administración. ${ }^{20}$

Los bienes son de Dios o de los pobres, y en atención a tales principios debe regirse la conducta del administrador, y quedar en claro, así, que intereses y necesidades se deben satisfacer con dichos bienes. ${ }^{21}$

Si bien los sacerdotes y los Obispos son simples administradores de los bienes de la Iglesia y por tanto estos bienes no les pertenecen a ellos a título personal, sí podían tomar lo necesario para su sustento. Sólo lo necesario, ya que permitirse tomar para lo superfluo significaba robar al pobre de lo necesario que le correspondía. $^{22}$

El Papa Lucio, a mediados del siglo III, expresaba en una carta enviada a los Obispos de España y de las Galias que se trataba de un grave pecado servirse del dinero o de propiedades de la Iglesia, condenando, de la misma forma, tanto al autor como a los que consentían en el delito. ${ }^{23}$

El principio "nihil innovetur", y que los presbíteros y los diáconos asuman el gobierno de la diócesis vacante debiendo abstenerse de las cuestiones más

${ }^{17}$ Cfr. A. Perlasca, Il concetto di..., op. cit., p. 31.

${ }^{18}$ Cf. Didascalia II, 25, 8, en: F. X. Funk, Didascalia et Constitutiones Apostolorum, Paderborn 1905, I, p. 96.

19 Cfr. A. Perlasca, Il concetto di..., op. cit., p. 31; Didascalia II, 44, 4, en: F. X. Funk, Didascalia et Constitutiones..., op. cit., I, p. 138.

${ }^{20}$ Cfr. F. R. Martínez Aguilar, Las normas sobre..., op. cit., p. 12.

${ }^{21}$ Cfr. A. Perlasca, Il concetto di..., op. cit., p. 34.

${ }^{22}$ Cfr. Didascalia II, 25, 1-2, en: F. X. Funk, Didascalia et Constitutiones..., op. cit., I, p. 92.

${ }^{23}$ Cfr. Epistola Lucii Papæ I. Ad Gallice atque Hispanice, Cap. 6, en: J. D. Mansi, Sacrorum Conciliorum Nova et Amplissima Collectio, Graz 1960, Vol. 1, col. 879. 
importantes, viene ya desde el siglo III, propuesto con fuerza durante la vacancia de la sede romana producida por la muerte del Papa Fabiano en el año 259. ${ }^{24}$

En el siglo III el patrimonio eclesiástico ya no está constituido solamente de dinero y de bienes consumibles, ya que hacia los últimos años del siglo II se atestigua la existencia de edificios ya no privados sino públicos reservados exclusivamente a las celebraciones litúrgicas y a la administración eclesiástica. El Obispo, en este período, era todavía visto como el único, e incontrolado, administrador de los bienes que venían donados por los fieles. ${ }^{25}$

Históricamente la administración de los bienes comunes de la Iglesia había sido confiada por los Apóstoles a los diáconos; y la función de ecónomo fue configurada en modo estable en este siglo III. ${ }^{26}$

\section{Reconocimiento de capacidad jurídica a la Iglesia (siglos IV y V)}

Pasados los primeros siglos de persecuciones la Iglesia había crecido y dejado de ser la primitiva comunidad doméstica. ${ }^{27}$

La necesidad de asegurar una correcta administración de los bienes de la Iglesia deviene urgente cuando, después del Edicto de Milán (año 313) ${ }^{28}$ y aquel Decreto de Constantino que permitió diversos legados hechos en esta época (año 321), el patrimonio eclesiástico comienza a crecer de modo notable. ${ }^{29}$

Se dieron normas relativas a la restitución de todos los bienes confiscados a la Iglesia durante las últimas persecuciones.

${ }^{24}$ Cfr. M. Mosconi, "Sede vacante nihil innovetur": i limiti all'esercizio dell'autorità nella condizione di vacanza della sede, QDE 17 (2004) 153.

25 Cfr. A. Perlasca, Il concetto di..., op. cit., p. 31-32.

${ }^{26}$ Cfr. J-P Schouppe, Elementi di Diritto Patrimoniale Canonico, Milano 1997, p. 170, nota 18. Este autor toma lo dicho de F. X. Wernz, Ius Canonicum, Tomus IV: De Rebus, vol. II, Romae 1935, p. 187, n. 737.

27 Cfr. F. R. Martínez Aguilar, Las normas sobre..., op. cit., p. 14.

${ }^{28}$ El tenor de este Edicto se conoce a través del texto que Licinio remitió al gobernador de Bitinia en el año 313. Ver M. Artola, Textos fundamentales para la Historia, Madrid 19858, p. 21-22.

${ }^{29}$ Cfr. M. Rivella, Participazione e corresponsabilità nella Chiesa, i consigli diocesani e parrocchiali, Milano 2000, p. 163. 
La Iglesia pasaba, con el citado Edicto de Milán en el derecho público estatal, a adquirir capacidad jurídica con todo lo que ello implicaba. ${ }^{30}$

La paz constantiniana hará que la Iglesia "pobre para los pobres" de los años anteriores vea aumentar progresivamente su patrimonio. Aparecen las "res sacrae". Los bienes de la Iglesia sólo se justificarán por sus fines de mantener el culto, el clero, y de atender a los más necesitados. ${ }^{31}$

Reconocida su personalidad pública, la Iglesia comenzó a recoger en sus manos un patrimonio, principalmente inmueble. ${ }^{32}$

Orígenes, al hablar del oficio de administrador que tiene el Obispo, precisaba que éste lo ejercía por medio de los presbíteros y diáconos, y se preocupaba por la mala administración que realizaban. ${ }^{33}$

El Obispo era la figura central en la administración, recolección y distribución de los bienes. ${ }^{34}$

El concilio de Ancyra (año 314) le permitía revocar un contrato efectuado para la Iglesia por un presbítero. ${ }^{35}$

Perlasca, refiriéndose a lo establecido por este concilio, comenta que urgía a los sacerdotes a no utilizar los bienes de la Iglesia sin una previa licencia del Obispo (canon 14), precisando que los bienes inmuebles eran inalienables durante la vacancia de la sede episcopal (canon 15$){ }^{36}$

El citado aumento de los bienes requirió personas idóneas, y en mayor número, para su manejo. ${ }^{37}$

Las conspicuas donaciones de los fieles formaron pronto un importante patrimonio eclesiástico, del cual hubieron de ocuparse por fuerza el derecho y la autoridad eclesiástica desde sus comienzos.

${ }^{30}$ Cfr. F. R. Martínez Aguilar, Las normas sobre..., op. cit., p. 14.

${ }^{31}$ Cfr. J. Pérez Llantada, Bienes Eclesiásticos, en: C. Corral Salvador (dir.) Diccionario de Derecho Canónico, Madrid 1989, p. 77.

32 Cfr. R. Bidagor, Los sujetos del patrimonio eclesiástico y el "ius eminens" de la Santa Sede, REDC 5 (1950) 26.

${ }^{33}$ Cfr. Origenis, Comment, in Matthaum., tomus XI, 9, en: J. P. Migne, Patrologia Graca, cursus completus, Paris 1857, vol. 13, col. 931-932.

${ }^{34}$ Cfr. F. R. Martínez Aguilar, Las normas sobre..., op. cit., p. 16.

${ }^{35}$ Cfr. Concilii Ancyrani (ex interpretatione Dionisii Exigui), canon 14, en: J. D. Mansi, Sacrorum Conciliorum Nova..., op. cit., vol. 2, col. 525.

${ }^{36}$ Cfr. A. Perlasca, Il concetto di..., op. cit., p. 36.

37 Cfr. F. R. Martínez Aguilar, Las normas sobre..., op. cit., p. 12. 
Los Santos Padres y los concilios buscaron y encontraron fórmulas jurídicas oportunas para regularla, defenderla y hacerla apta a aquel fin primordial por el cual los fieles daban sus bienes y la Iglesia los aceptaba. El patrimonio eclesiástico fue sujetado por los concilios a estrecha vigilancia y ordenación jurídica; los bienes de la Iglesia se debían conservar, pues estaban -y están- vinculados a un fin del cual no se podían desprender. ${ }^{38}$

En la nueva realidad en que se encontró la Iglesia después de la concesión de la libertad religiosa a todos los habitantes del imperio es posible entrever un importante desarrollo y transformación en ella misma, y también en el derecho canónico y en sus fuentes. La paz constantiniana permitió a la Iglesia fijar las prescripciones relativas a la fe y a la disciplina.

Los concilios pasaron a ser una institución de carácter público y general. En estas asambleas de Obispos se sancionaron normas disciplinares, litúrgicas y organizativas; siendo consignadas las decisiones y disposiciones en los denominados cánones. ${ }^{39}$

Por ejemplo, en el Concilio de Gangra al norte de Turquía (año 324), se señalaba que al que vendiera propiedades de la Iglesia sin el expreso consentimiento del Obispo, figura central en la administración de los bienes, se penalizaría con anatema. ${ }^{40}$

Las disposiciones de los concilios contribuyeron a completar la mirada sobre la normativa en materia de administración. En general se trata de normas bastante puntuales que tocan aspectos precisos de ella.

Los primeros textos cristianos que muestran un estilo legislativo son los cánones dictados por los Concilios. Desde el siglo III hay datos de actividad conciliar. ${ }^{41}$

Grazian nos recuerda que la indicación más antigua, y reiterada en la legislación, es aquella que impone una figura, distinta del Obispo, que se ocupe del cuidado de los bienes temporales. ${ }^{42}$

En el Concilio de Nicea (año 325), vista la expansión producida, pasa a ser considerada necesaria la figura del ecónomo en cada una de las Iglesias, y se

${ }^{38}$ Cfr. R. Bidagor, Los sujetos del..., op. cit., 27.

${ }^{39}$ Cfr. B. E. Ferme, Introducción a la Historia de las Fuentes del Derecho Canónico. El Derecho Antiguo hasta el Decretum de Graciano, Buenos Aires 2006, p. 67-68.

${ }^{40}$ Cfr. Concilii Gangrensis (ex interpretatione Dionisii Exigui), canon 7, en: J. D. Mansi, Sacrorum Conciliorum Nova..., op. cit., vol. 2, col. 1107.

${ }^{41}$ Cfr. P. Lombardía, Lecciones de Derecho..., op. cit., p. 29.

${ }^{42}$ Cfr. F. Grazian, La nozione di amministrazione e di alienazione nel Codice di diritto canonico, Roma 2002, p. 71-72. 
le encomendarán, precisa el canon 68 de la versión árabe de ese Concilio, casas, granjas, comestibles, vestimenta, ornamentos, etc. ${ }^{43}$

Él, además de cuidar tales bienes, en la medida de lo posible, debía aumentarlos y repartirlos así entre las parroquias rurales. ${ }^{44}$

En el Concilio de Antioquía (año 341) se obligaba al Obispo a servirse de una serie de personas para que le ayudaran en su administración, debiendo estar los presbíteros y diáconos perfectamente al tanto de lo que pertenecía a la Iglesia. ${ }^{45}$

Los presbíteros y diáconos debían conocer, y de alguna forma autorizar, la entrega de los bienes que el Obispo prodigase. ${ }^{46}$

El Obispo, administrador libre y absoluto, quedaba vinculado por las normas que legislaban los concilios. ${ }^{47}$

Martínez Aguilar precisa que hasta se llegó a decir que si los presbíteros y diáconos desconocían la donación efectuada por el Obispo ésta no era lícita; señalando este autor que legislación de este tipo no dejaba dudas acerca de que el Obispo no era más que un parcial y temporal dueño de las cosas de Dios, jamás su dueño absoluto. ${ }^{48}$

En el canon 17 del IV Concilio de Cartago (año 398) se requería al Obispo que encomendara las responsabilidades del cuidado y mantenimiento de viudas, huérfanos y forasteros a su archipresbítero o archidiácono. ${ }^{49}$

El archidiácono era el asistente y ayudante inmediato del Obispo, ${ }^{50}$ y ayudaba a éste en el cuidado de los intereses temporales de la Iglesia.

${ }^{43}$ Cfr. Concilii Nicaeni (ex nova ex arabico versione), canon 68, en: J. D. Mansi, Sacrorum Conciliorum Nova..., op. cit., vol. 2, col. 1003.

${ }^{44}$ Cfr. Concilii Nicaeni (Eorumdem Sanctorum Patrum CCCXVIII. Alia Varia Ecclesiastica.. Constitutiones), caput 6, en: J. D. Mansi, Sacrorum Conciliorum Nova..., op. cit., vol. 2, col. 1021.

${ }^{45}$ Cfr. Concilii Antiocheni (ex interpretatione Dionisii Exigui), canon 24, en: J. D. Mansi, Sacrorum Conciliorum Nova..., op. cit., vol. 2, col. 1327.

${ }^{46}$ Cfr. Ibidem, canon 25, en: J. D. Mansi, Sacrorum Conciliorum Nova..., op. cit., vol. 2, col. 1328 .

${ }^{47}$ Cfr. Concilium Antiochenum I (Gentiano Herveto interprete), canon 24, en: J. D. Mansi, Sacrorum Conciliorum Nova..., op. cit., vol. 2, col. 1318.

${ }^{48}$ Cfr. F. R. Martínez Aguilar, Las normas sobre..., op. cit., p. 16.

${ }^{49}$ Cfr. Concilium Carthaginense (nomine et temporis ordine quartum), canon 17, en: J. D. Mansi, Sacrorum Conciliorum Nova..., op. cit., vol. 3, col. 952.

50 San Jerónimo expresaba: "Certe qui primus fuerit ministrorum, quia per singula concionatur in populos, et a Pontificis latere non recedit, injuriam putat, si presbyter ordinetur: et non meminit mensarum et viduarum minister, in obsequium se et ministerium non solum sacerdotum, sed et viduarum, et pauperum delegatum". S. Eusebii Hieronymi, commentariorum 
Encontramos alusiones al archidiácono como artífice de todo lo que se refiere a la economía de la Iglesia, ${ }^{51}$ al igual que la mención del castigo aplicado a un Obispo por echar a su archidiácono, y no permitirle, de esa forma, mantener la vista sobre los bienes. ${ }^{52}$

El archidiácono, nombrado por el Obispo, tenía altas funciones litúrgicas. Él vigilaba al clero y velaba por el respeto de la disciplina eclesiástica, ocupándose, como agente del Obispo, tanto de las personas como de los bienes. ${ }^{53}$

El Obispo y el archidiácono consideraron necesario, con la expansión de la Iglesia y el consiguiente aumento de sus competencias temporales, nombrar a un nuevo tipo de personal para el ministerio de la administración de bienes temporales; y este ministro se llamó "oeconomus", o mayordomo. La relación entre el Obispo y el archidiácono debió ser muy estrecha, pero se carece de legislación que nos precise ese aspecto. Se señala que el archidiácono terminó constituyendo un poder contrapuesto al del Obispo. ${ }^{54}$

Con el acrecentamiento de la riqueza también la estructura administrativa se amplía y se diversifica según las necesidades y las regiones. El número de los colaboradores del Obispo en la administración del patrimonio dependía de la importancia de la comunidad y de los bienes a administrar. El Obispo necesitaba contar con personal especializado y organizado. ${ }^{55}$

in Ezechielem (Lib. XIV, cap. XLVIII), en: J. P. Migne, Patrologia Latina, cursus completus, Paris 1844 , vol. 25 , col. 484 b.

${ }^{51}$ Cfr. S. Leonis Magni, Epistola 111 (Ad Marcianum Augustum), cap. 2, en: J. P. Migne, Patrologia Latina ..., op. cit., vol. 54, col. 1021-1022.

${ }^{52}$ Cfr. Gelasii Papae I (Gelasius respecto et Leonino Episcopis), en: J. P. Migne, Patrologia Latina ..., op. cit., vol. 59, col. 100.

${ }^{53}$ Cfr. B. Basdevant-Gaudemet, Larchidiacre et l'archiprêtre d'après le Décret de Gratien, en: Iudex et Magister. Miscelánea en honor al Pbro. Nelson C. Dellaferrera. Tomo I Historia del Derecho, Buenos Aires 2008, p. 85.

${ }^{54}$ Cfr. F. R. Martínez Aguilar, Las normas sobre..., op. cit., p. 7; A. Perlasca, La Curia Diocesana: Fundamentos teológicos y administrativos, en: La curia diocesana. Aspectos jurídicos $y$ pastorales, Buenos Aires 20113, p. 10.

55 Cfr. A. Perlasca, Il concetto di..., op. cit., p. 38; nota 107. Sobre el particular, Perlasca cita la siguiente consideración de Orígenes: "Non enim simpliciter de rebus ecclesiasticis dare oportet [...] sed ut prudenter intelligamus indigentium causas propter quas sunt indigentes; et uniuscujusque dignitatem quomodo advocatus est [educatus], quantum necessarium habet, vel propter quam causam indiget. Non ergo similiter est agendum in eis qui ab infantia duriter sunt educati et stricte, et in eis qui large et deliciose nutriti sunt, et postea ceciderunt". Origenis, in Matthaum, commentariorum series, en: J. P. Migne, Patrologia Graca ..., op. cit., vol. 13, col. 1697. 
En los Canones Sanctorum Apostolorum se señala que el Obispo, conservando su libertad en la administración de los bienes de la Iglesia, no lleve personal y directamente la administración del patrimonio, sino que se sirva de otras personas que tengan ello a su cargo. ${ }^{56}$

En estos Canones vemos también cómo se urge a los Obispos y a los sacerdotes a distinguir, en forma precisa, los bienes personales de aquellos de la Iglesia, para que estos últimos no se perdieran. ${ }^{57}$

Los Obispos debían administrar todos los bienes eclesiásticos como ecónomos de Dios. ${ }^{58}$

Se encontraba firme el principio que los bienes donados a la Iglesia no pertenecen a los eclesiásticos, los cuales sólo desempeñan el cargo de administradores. $^{59}$

En las Constituciones Apostólicas se precisaba que el Obispo era el administrador de todas las cosas eclesiásticas, prohibiéndosele terminantemente la venta de propiedades pertenecientes a la Iglesia, o darlas a sus parientes, salvo que éstos fueran pobres. ${ }^{60}$

Si bien se señalaba que nadie le pida cuentas, ni supervise cómo él dispensa o realiza su administración, ${ }^{61}$ ésta no la debía hacer por sí mismo sino por medio de presbíteros y diáconos. ${ }^{62}$

El Obispo podía disponer libremente de sus bienes personales para después de su muerte, por eso era necesario que se distinguieran éstos, si los tuviese, de los bienes que eran del Señor ${ }^{63}$.

${ }^{56}$ Cfr. Theodori Balsamonis, Canones Sanctorum Apostolorum, canon 4, en: J. P. Migne, Patrologia Graca ..., op. cit., vol 137, col. 42.

${ }^{57}$ Cfr. Theodori Balsamonis, canon 40, en: J. P. Migne, Patrologia Graca ..., op. cit., vol. 137, col. 122.

${ }^{58}$ Cfr. Theodori Balsamonis, canon 38, en: J. P. Migne, Patrologia Graca ..., op. cit., vol. 137, col. 118.

59 Cfr. A. Perlasca, Il concetto di..., op. cit., p. 33.

${ }^{60}$ Cfr. M. Metzger, Les Constitutions Apostoliques, Tome III, Livres VII et VIII, Paris 1987, VIII, 47, 38. 35,4 .

${ }^{61}$ Cfr. M. Metzger, Les Constitutions Apostoliques, Tome I, Livres I et II, Paris 1985, II,

${ }^{62}$ Cfr. Ibidem, VIII, 47, 39.

${ }^{63}$ Cfr. Ibidem, VIII, 47, 40. 
Queda claro que los Pastores no son dueños de los bienes, sino que de ellos son sus administradores, sus dispensadores, sus procuradores; y si los usan para su provecho propio recibirán el reproche de Dios. ${ }^{64}$

$\mathrm{Al}$ inicio del siglo $\mathrm{V}$ se sentía la exigencia de una radical reforma, ya que, no obstante los correctivos introducidos en la administración del patrimonio de la Iglesia, la discrecionalidad del Obispo en la destinación de los bienes permanecía todavía muy amplia, siendo esto fuente de abusos. ${ }^{65}$

Los Concilios de Hipona (año 419) ${ }^{66}$ y de Cartago XVIII (año 421), ${ }^{67}$ en conformidad con lo legislado en los Concilios de Cartago $I^{68}$ y V, ${ }^{69}$ establecieron normas que impusieron restricciones sobre la actividad administrativa del Obispo.

El Concilio de Calcedonia (año 451), convocado por orden del Emperador Marciano después del latrocinio de Efeso (año 449), debe sancionar el comportamiento del clero que saqueaba los bienes del Obispo difunto. ${ }^{70}$

En sede vacante, como se observa, no siempre se demostrará estar a la altura de una gestión eficaz, dejando espacio a la realización de acciones no honestas. ${ }^{71}$

En el canon 25 de este Concilio de Calcedonia, con referencia a que la Iglesia no debe permanecer privada de su Obispo por más de tres meses, encontramos

${ }^{64}$ Cfr. Ibidem, II, 25, 2-3.

${ }^{65}$ Cfr. A. Perlasca, Il concetto di..., op. cit., p. 40.

${ }^{66}$ Cfr. Concilium Hipponiregiense, canon 9, en: J. D. Mansi, Sacrorum Conciliorum Nova..., op. cit., vol. 4, col. 442.

${ }^{67}$ Cfr. Concilium Carthaginense (sub Aurelio XVIII), canon 9, en: J. D. Mansi, Sacrorum Conciliorum Nova..., op. cit., vol. 4, col. 450.

${ }^{68}$ El IV Concilio de Cartago (año 398) declaraba inválida (irrita), salvo acuerdo y suscripción del clero, la donación, venta o transferencia de los bienes eclesiásticos hecha por el Obispo. Cfr. Concilium Carthaginense (nomine et temporis ordine quartum), canon 32, en: J. D. Mansi, Sacrorum Conciliorum Nova..., op. cit., vol. 3, col. 954.

69 En V Concilio de Cartago (año 398) vemos que si alguna propiedad o bien debía venderse, el Obispo más anciano, de conformidad con otros pares de la misma región, tenía que saberlo y estar, de antemano, en total acuerdo; y si esto no fuera posible, deberían saberlo en forma inmediata después de producida la venta. Cfr. Concilium Carthaginense (nomine quintum), canon 4, en: J. D. Mansi, Sacrorum Conciliorum Nova..., op. cit., vol. 3, col. 969.

${ }^{70}$ Cfr. Concilium Chalcedonense, canon 22, en: G. Alberigo et alli, Conciliorum Oecomenicorum Decreta, Bologna 1991, p. 97.

${ }^{71}$ Cfr. M. Mosconi, “Sede vacante nihil ..., op. cit., 150. 
que los réditos de la Iglesia vacante deben ser conservados intactos por el administrador de la misma. ${ }^{72}$

A su vez, el canon 26 constata que los Obispos administran los bienes eclesiásticos sin un ecónomo, por lo tanto dispone que en adelante en cada Iglesia que tiene Obispo propio haya también un ecónomo, escogido del mismo clero, que administre los bienes bajo la autoridad del mismo Obispo, a fin de que los bienes de la Iglesia no sean dilapidados; si el Obispo no actuaba en conformidad quedaba sujeto a los divinos cánones. ${ }^{73}$

Tal normativa no sólo era necesaria por una exigencia administrativa, sino para evitar la desaparición o dispersión de los bienes de la Iglesia y el favorecimiento de beneficios personales. Enseguida se multiplicaron las leyes en los concilios sobre la administración de los bienes eclesiásticos. ${ }^{74}$

La finalidad de la citada norma era doble: por una parte impedir que se dilapiden los bienes eclesiásticos, y por otra parte que sea salvaguardada la dignidad episcopal, en modo que sean evitadas indecorosas sospechas o reproches. ${ }^{75}$

El poder de este colaborador del Obispo es expresado con la palabra "dispensare". Con el ecónomo distinto del Obispo, se comienza a dar un significado preciso a la administración, en oposición particularmente a la alienación. Administrar es conservar, tutelar, los bienes y aplicarlos para los fines bajo el gobierno del Obispo. Son importantes, particularmente, el inventario y la rendición, en modo que el superior responsable pueda tener el control sobre los bienes y sobre todo evitar la alienación o la perdida de ellos. ${ }^{76}$

Hasta el siglo V puede considerarse que duró este primer período de administración episcopal. ${ }^{77}$

Es de mencionar lo dispuesto por el Papa León Magno referente a: "Sine exceptione decernimus, ne quis episcopus de rebus ecclesiae suae quicquam donare, vel conmutare, vel vendere audeat, nisi forte aliquid horum faciat, ut meliora

${ }^{72}$ Cfr. Concilium Chalcedonense, canon 25, en: G. Alberigo et alli, Conciliorum Oecomenicorum Decreta ..., op. cit., p. 98.

${ }^{73}$ Cfr. Ibidem, canon 26, en: G. Alberigo et alli, Conciliorum Oecomenicorum Decreta..., op. cit., p. 99.

${ }^{74}$ Cfr. A. Perlasca, Il concetto di..., op. cit., p. 39; V. De Paolis, I beni temporali..., op. cit., p. 62-63.

${ }^{75}$ Cfr. F. Grazian, La nozione di..., op. cit., p. 72.

${ }^{76} \mathrm{Cfr}$. V. De Paolis, Alcune osservazioni sulla nozione di amministrazione dei beni temporali della Chiesa, "Periodica" 88 (1999) 94-95.

77 Cfr. F. R. Martínez Aguilar, Las normas sobre..., op. cit., p. 17. 
prospiciat, et cum totius cleri tractatu atque consensu id eligat, quod non sit dubium profuturum ecclesiae". ${ }^{78}$

También es de citar que, en el año 475, el Papa Simplicio dispuso que los réditos del fondo patrimonial eclesiástico no debían distribuirse según el arbitrio del Obispo. Estos réditos debían clasificarse en cuatro partes: una destinándose al Obispo, una al clero de la comunidad, una a los pobres, y otra para la construcción y mantenimiento de los edificios de culto. ${ }^{79}$

Estas normas, al ser ratificadas en el año 494 por el Papa Gelasio y sostenidas por los Romanos Pontífices posteriores, se transformaron en leyes universales. $^{80}$

\section{Tentativas y tendencias a la disgregación del único patrimonio diocesano (siglos $\mathrm{VI}$ al $\mathrm{X}$ )}

A partir del siglo VI se comienzan a percibir tentativas y tendencias a la disgregación del único patrimonio diocesano. Nos encontramos con la erección de parroquias de propiedad privada o señorial por el desarrollo de la Iglesia en los medios rurales.

La parroquia rural tuvo su origen para proveer a las necesidades religiosas del pueblo fiel cuando el cristianismo se difundió en la campaña. También en la ciudad se crearon poco a poco las parroquias, a cada una de las cuales venía destinado un sacerdote para la cura de almas.

Por vía directa o indirecta, el patrimonio eclesiástico siguió acrecentándose. Éste se transformaba en sistema de pluralismo patrimonial eclesiástico institucional al ir perdiendo su unicidad. ${ }^{81}$

Los Obispos no podían actuar autónomamente para la alienación de los bienes de la Iglesia. ${ }^{82}$

${ }^{78}$ Cfr. Leonis I, Epistola 17, en: J. P. Migne, Patrologia Latina ..., op. cit., vol. 54, col. 705.

79 Cfr. Simplicius Papa, Epistola 3: Ad Florentium et Equitium Episcopos, en: J. P. Migne, Patrologia Latina ..., op. cit., vol. 58, 37.

${ }^{80}$ Cfr. F. R. Martínez Aguilar, Las normas sobre..., op. cit., p. 18.

${ }^{81}$ Cfr. F. R. Martínez Aguilar, Las normas sobre..., op. cit., p. 20.

${ }^{82}$ Cfr. Concilium Agathense, canon 7 (año 560), en: J. D. Mansi, Sacrorum Conciliorum Nova..., op. cit., vol. 8, col. 325. 
El Concilio Aurelianense V (año 549) prohibía a los administradores de la iglesia, de los monasterios y de los hospitales violar la propiedad legítimamente adquirida por parte de la Iglesia. ${ }^{83}$

El canon 33 del Concilio Toledano IV (año 633) prohibía a los Obispos, recordando el carácter sacro de los bienes de la Iglesia, tomar, "in proprium emolumentum", una cantidad superior a la prescrita por el derecho. ${ }^{84}$

En una extensión al metropolitano de la prohibición que el Concilio de Calcedonia, en su canon 22, establecía para los clérigos, el canon 35 del Concilio Trullano (año 691) establecía que no era lícito a ningún metropolitano, a la muerte de un Obispo sufragáneo, sustraer de su sede los bienes pertenecientes al difunto o a su iglesia; debiendo, en el caso de que no quede ningún clérigo en dicha Iglesia, conservar esos bienes intactos para entregárselo al Obispo que sea ordenado. ${ }^{85}$

La invitación a los sacerdotes a administrar con la máxima atención los bienes eclesiásticos la podemos encontrar, entre otros, en el Concilio Toledano II (año 531), ${ }^{86}$ en el Concilio Arvernense (año 535), ${ }^{87}$ en los Concilios Aurelianenses III (año 538) ${ }^{88}$ y IV (año 541), ${ }^{89}$ en los Concilios Parisienses III (año $557)^{90}$ y VI (año 829) ${ }^{91}$, y en el Concilio Turonense II (año 567). ${ }^{92}$

${ }^{83}$ Cfr. Concilium Aurelianense V, canon 13, en: J. D. Mansi, Sacrorum Conciliorum Nova..., op. cit., vol. 9, col. 131.

${ }^{84}$ Cfr. Concilium Toletanum IV, canon 33, en: J. D. Mansi, Sacrorum Conciliorum Nova..., op. cit., vol. 10, col. 628.

${ }^{85}$ Cfr. A Perlasca, Il concetto di..., op. cit., p. 44 y nota 124.

${ }^{86}$ Cfr. Concilium Toletanum II, canon 4, en:. J D. Mansi, Sacrorum Conciliorum Nova..., op. cit., vol. 8, col. 786.

${ }^{87}$ Cfr. Concilium Arvernense, canon 5, en: J. D Mansi, Sacrorum Conciliorum Nova..., op. cit., vol. 8, col. 860-861.

${ }^{88}$ Cfr. Concilium Aurelianense III, canon 22, en: J. D. Mansi, Sacrorum Conciliorum Nova..., op. cit., vol. 9, col. 18.

${ }^{89}$ Cfr. Concilium Aurelianense IV, canon 25, en: J. D. Mansi, Sacrorum Conciliorum Nova... op. cit., vol. 9, col. 117.

${ }_{90}$ Cfr. Concilium Parisiense III, canon 1, en: J. D. Mansi, Sacrorum Conciliorum Nova..., op. cit., vol. 9, col. 743-745.

${ }^{91}$ Cfr. Concilium Parisiense VI, canon 14, en: J. D. Mansi, Sacrorum Conciliorum Nova..., op. cit., vol. 14, col. 548-549.

${ }_{92}$ Cfr. Concilium Turonense II, canon 24, en: J. D. Mansi, Sacrorum Conciliorum Nova..., op. cit., vol. 9, col. 803-804. 
El Concilio Niceo II (año 787), en concordancia con el canon 26 del Concilio de Calcedonia, expresaba la obligación de observar todos los sagrados cánones y por ello mantener inmutable la norma de que en cada Iglesia haya un ecónomo. Si el Obispo no lo ha nombrado puede imponerlo el Obispo de Constantinopla. Lo mismo puede hacer el metropolitano en sus diócesis sufragáneas, debiendo ser esta norma también observada en los monasterios. ${ }^{93}$

Este sistema institucional comprende, en los siglos VIII al XII, el arreglo patrimonial definitivo y asume el nombre de "beneficium ecclesiasticum". ${ }^{4}$

El uso de los bienes de la Iglesia de parte de los eclesiásticos es de mera administración y disposición: "secundum canonicam auctoritatem, sanctorumque patrum dicta et exempla, administrare vel dispensare." ${ }^{.5}$

Sólo los sacerdotes, indica Bidagor citando el canon 8 del Concilio Romano (año 502) y el canon 8 del Concilio Aquisgranense II (año 836), indiscutiblemente tienen de Dios el cuidado y poder de disponer del patrimonio eclesiástico. ${ }^{96}$

El Concilio Constantinopolitano IV (año 869-870) impedía la venta o cualquier otro acto que llevase a la enajenación de objetos preciosos o bienes de culto - "vasa sacra"-; salvo el caso que sea para el rescate de presos. Las rentas eclesiásticas del Obispo, a su vez, debían servir a su sustento, a la alimentación de los pobres, $\mathrm{y}$ al socorro de los peregrinos. ${ }^{97}$

En Francia, el Concilio de Trosly (año 909) dispuso que el gobierno y la distribución de las ofrendas de los fieles debían permanecer firmemente en poder de los sacerdotes, aunque sujetos al poder y la dirección de los Obispos. ${ }^{98}$

Durante todo este primer milenio la masa de los bienes de las varias diócesis eran comunes y administrados o gestionados unitariamente por el Obispo, o por aquellos que él destinaba para esa finalidad. Las rentas provenientes de esa masa se repartían según las exigencias y finalidades. Pero luego, debido a la mutación de las circunstancias históricas y al crecimiento de los bienes de la Iglesia,

${ }^{93}$ Cfr. Concilium Nicaenum II, canon 11, en: G. Alberigo et alli, Conciliorum Oecomenicorum Decreta ..., op. cit., p. 147.

94 Cfr. F. R. Martínez Aguilar, Las normas sobre..., op. cit., p. 24.

95 Concilium Parisiensi vI, caput 15, en: J. D. Mansi, Sacrorum Conciliorum Nova..., op. cit., vol. 14 , col. 549 .

${ }^{96}$ Cfr. R. Bidagor, Los sujetos del..., op. cit., 28.

97 Cfr. Concilium Constantinopolitanum IV, canon 15, en: G. Alberigo et alli, Conciliorum Oecomenicorum Decreta ..., op. cit., p. 177, 18-25.

98 Cfr. Concilium Trosleyanum, canon 6, en: J. D. Mansi, Sacrorum Conciliorum Nova..., op. cit., vol. 18, col. 280. 
se fueron dividiendo no solo las rentas sino los mismos bienes; creándose, así, la necesidad de regular las varias administraciones y de articularlas al interno. ${ }^{99}$

Con la división de los diversos fines institucionales de los bienes de la Iglesia continúa permaneciendo firme el principio de la única masa de bienes diocesana. Pero de esta repartición de las rentas sigue pronto la división del mismo patrimonio eclesiástico en múltiples entes, calificados en la doble categoría de "universitates personarum" y "universitates rerum". Al frente de cada una de estas "universitates" se pone un responsable, que tiene la tarea ya de gobernarla que de administrarle los bienes. ${ }^{100}$

La disponibilidad de medios económicos para desarrollar en modo adecuado la propia misión no fue puesta en discusión. Paulatinamente que se advierte la necesidad de multiplicarse la comunidad cristiana en diversos lugares y de encomendárselas a los presbíteros, no disminuye la responsabilidad del Obispo por la administración de los bienes. Se comienza a distinguir el oficio propio del que administra los bienes de la Iglesia y el deber de la supervisión del Obispo para asegurarse que todo se produzca en conformidad a la naturaleza y a los fines de la Iglesia. ${ }^{101}$

Respecto a la división del mismo patrimonio eclesiástico en múltiples entes, el Obispo por una parte tiene también un poder administrativo sobre los bienes de la diócesis y por otra parte tiene la responsabilidad sobre los entes que a él son subordinados.

Se delinea la necesidad de comenzar a distinguir los diversos perfiles bajo los cuales los bienes recaen bajo la autoridad competente. Las diversas competencias se determinaban en base a los diversos poderes: se distingue el poder normativo acerca de los bienes, aquel judicial, y aquel administrativo; aquel de vigilancia y de control, distinto de aquel propiamente administrativo, de custodia, tutela, desarrollo y protección de los bienes.

La palabra administrar comienza a asumir un significado técnico distinto de otros significados más genéricos. Con el andar del tiempo y con el cambiar de las circunstancias se realiza la diferencia entre actos de administración

99 Cfr. F. Grazian, La nozione di..., op. cit., p. 66.

100 Cfr. V. De Paolis, Alcune osservazioni sulla..., op. cit., 95.

101 Cfr. A. Longhitano, L’amministrazione dei beni: la funzione di vigilanza del Vescovo diocesano (cann. 1276-1277 CIC), en: I beni temporali della Chiesa, Città del Vaticano 1999, p. $84-85$. 
ordinaria y extraordinaria; y al interior de la misma administración ordinaria, más tarde se precisa que puede haber algunos que tengan un mayor relieve.

En este variar de situaciones, en la medida en la cual se distingue los roles del Obispo, del superior de la persona jurídica y del administrador de ella, se comienza a distinguir más concretamente las diversas competencias, en los diversos sectores del poder de jurisdicción eclesiástica. ${ }^{102}$

\section{Conclusión}

Durante el transcurso del primer milenio puede observarse la preocupación por el cuidado y la debida aplicación de los bienes eclesiásticos. Las disposiciones citadas son claras en tal sentido.

También se ve la responsabilidad del Obispo en la administración de los bienes. Responsabilidad que no disminuye ante la necesidad de multiplicarse la comunidad cristiana en diversos lugares y de encomendárselas a los presbíteros.

En el libro V del Código de Derecho Canónico de Juan Pablo II, "De Bonis Ecclesiae Temporalibus", pueden verse reflejadas varias de las mencionadas disposiciones. Por ejemplo, y al solo efecto ilustrativo, en los cánones 1254, 1276, 1277,1281 y 1282.

Pero no solamente allí se pueden encontrar estas disposiciones. El principio "nihil innovetur" en sede episcopal vacante está en el canon 428.

La obligación que pesa sobre todo Obispo de nombrar un ecónomo en su diócesis, normativa que no estaba en el Código de 1917, la vemos en el canon $494 \$ 1$.

Resultaría extenso realizar la referencia puntual de cada uno de los cánones que se compadecen con las disposiciones vistas. Recorriendo la lectura del Código van surgiendo con toda claridad las mismas.

${ }^{102}$ Cfr. V. De Paolis, Alcune osservazioni sulla..., op. cit., 95-96. 


\section{Bibliography}

\section{Sources}

Alberigo G. et alii, Conciliorum Oecomenicorum Decreta, Bologna 1991.

Artola M., Textos Fundamentales para la Historia, Madrid $1985^{8}$.

Funk F. X., Didascalia et Constitutiones Apostolorum, Paderborn 1905.

Mansi J. D., Sacrorum Conciliorum Nota et Amplissima Collectio, Graz 1960.

Metzger M., Les Constitutions Apostoliques, Tome I, Livres I et II, Paris 1985; Tome III, Livres VII et VIII, Paris 1987.

Migne J. P., Patrologiae Graecae, cursus completus, Paris 1857.

Migne J. P., Patrologiae Latinae, cursus completus, Paris 1844.

Ruiz Bueno D., Padres Apostólicos, Madrid $1985^{5}$.

\section{Authors}

Barile A., De Patrimoniali Ecclesiae Regimine, Historica vel juridica praesupposita, Roma 1925.

Basdevant-Gaudemet B., L'archidiacre et l'archiprêtre d'après le Décret de Gratien, en: Iudex et Magister. Miscelánea en honor al Pbro. Nelson C. Dellaferrera. Tomo I Historia del Derecho, Buenos Aires 2008, p. 85-107.

De Paolis V., I beni temporali della Chiesa, Bologna 1995.

De Paolis V., Les biens temporels au regard du code de droit canonique, "Lannée Canonique" 47 (2005) 7-35.

Di Nicco J. A., El Ecónomo Diocesano. Precisiones acerca de este oficio eclesiástico. Propuesta sobre el parágrafo tercero del canon 494, Buenos Aires 2012.

Ferme B. E., Introducción a la Historia de las Fuentes del Derecho Canónico. El Derecho Antiguo hasta el Decretum de Graciano, Buenos Aires 2006.

Grazian F., La nozione di amministrazione e di alienazione nel Codice di diritto canonico, Roma 2002.

Martínez Aguilar F. R., Las normas sobre la administración económica en las Iglesias particulares. En especial su aplicación en el derecho particular del cono sur latinoamericano, Montevideo 1998.

Mosca V., Il ruolo della gerarchia nell'amministrazione comunionale dei beni della chiesa, en: Iustitia in Caritate, Cittá del Vaticano 2005, p. 387-409.

Mosconi M., "Sede vacante nihil innovetur": i limiti all'esercizio dell'autorità nella condizione di vacanza della sede, QDE 17 (2004) 146-175.

Perlasca A., Il concetto di bene ecclesiastico, Roma 1997.

Perlasca A., La Curia Diocesana: Fundamentos teológicos y administrativos, en: La curia diocesana. Aspectos jurídicos y pastorales, Buenos Aires $2011^{3}$, p. 9-25. 
Rivella M., Partecipazione e corresponsabilità nella Chiesa, $i$ consigli diocesani e parrocchiali, Milano 2000.

Schouppe J. P., Elementi di Diritto Patrimoniale Canonico, Milano 1997. 